\title{
The Primary Care Research Landscape and its Relationship with Clinical Practice: A Scientometric Analysis
}

\author{
O Panorama da Investigação em Cuidados de Saúde Primários e a \\ sua Relação com a Prática Clínica: Uma Análise Cientométrica
}

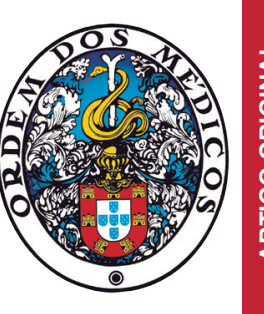

\author{
Salomé APITZ $\triangle^{1}$, Pedro FONTOURA ${ }^{2}$ \\ Acta Med Port 2022 Jan;35(1):3-11 - https://doi.org/10.20344/amp.15262
}

\section{ABSTRACT}

Introduction: It is unclear if research published in primary care journals aligns with the broad spectrum of problems managed in primary care practice. The aim of this study was to analyse publication trends concerning the burden of medical conditions reported in primary care journals, and to compare these findings with the burden of problems seen in clinical practice, in order to identify research gaps.

Material and Methods: Scientometric tools were used to analyse 9956 articles of primary care journals indexed in MEDLINE. Through keyword analysis, a relations map was built. Literature review and a primary care database were used to identify active problems and reasons for visiting a family physician. Rankings and frequencies of research output and conditions were compared.

Results: Keyword analysis identified five clusters of publication trends: cardiovascular conditions and conditions related with unhealthy lifestyles; mental disorders; infections; oncology and health management. By comparing publications with clinical problems, the fields of orthopaedics, endocrinology/metabolism, gastroenterology/hepatology, dermatology, ophthalmology, and the respiratory system show the biggest gaps. Through the relations map, more concrete potential research topics were identified such as palliative care, chronic pain, insomnia, antibiotic prescribing, burnout, osteoporosis, osteoarthritis, and COVID-19.

Conclusion: The distribution of publications in primary care journals is distinct from the burden of problems faced in clinical practice and reasons for visiting a family physician. The use of scientometric tools to identify publication trends and their comparison with common problems could be a strategy to identify areas with research gaps in primary care.

Keywords: Bibliometrics; Database Management Systems; Primary Health Care; Publishing

\section{RESUMO}

Introdução: Desconhece-se se a investigação publicada na área dos cuidados de saúde primários está alinhada com os problemas geridos na prática clínica. Pretendemos analisar as tendências de publicação das revistas científicas de cuidados de saúde primários no que diz respeito a problemas médicos e comparar os resultados com a prevalência dos problemas na prática, para encontrar lacunas investigacionais.

Material e Métodos: Utilizando ferramentas cienciométricas, analisámos 9956 artigos de revistas de cuidados de saúde primários indexadas à MEDLINE. Através da análise de palavras-chave, construímos um mapa de relações. Identificámos os problemas prevalentes através da revisão da literatura e de uma base de dados dos Cuidados de Saúde Primários. Comparámos as áreas de investigação com problemas ativos e motivos de consulta quanto à frequência e ranking.

Resultados: Identificámos cinco grupos de tendências de publicação: doenças cardiovasculares/condições relacionadas com estilos de vida não saudáveis; patologia mental; infeções; oncologia; e gestão em saúde. Comparando publicações com problemas clínicos, as áreas de ortopedia, endocrinologia/metabolismo, gastrenterologia/hepatologia, dermatologia, oftalmologia e sistema respiratório apresentam as maiores lacunas. Através do mapa de relações, encontrámos potenciais áreas de investigação mais concretas, como cuidados paliativos, dor crónica, insónia, burnout, osteoporose, artrose, COVID-19.

Conclusão: A distribuição das publicações em revistas de Medicina Geral e Familiar diverge da proporção dos problemas e motivos de consulta. A identificação de tendências de publicação com ferramentas cienciométricas e a sua comparação com problemas comuns pode ser uma estratégia para reconhecer lacunas de investigação.

Palavras-chave: Bibliometria; Cuidados de Saúde Primários; Publicação; Redes de Comunicação de Computadores

\section{INTRODUCTION}

Primary health care covers a broad spectrum of conditions which reflect the prevalence of diseases in the general population. ${ }^{1}$ The research activity in this field has increased noticeably over recent years, and the internet has made information widely available. With the increasing amount of evidence, clinicians must make an increasing effort to remain up to date. ${ }^{2}$ Primary care journals can respond to physicians' needs by publishing evidence that covers recent advances on a broad range of common clinical topics. Some authors stress the importance of identifying research needs in clinical practice in order to improve the alignment between academia and clinical practice. ${ }^{3-6}$ Therefore, research efforts can impact positively on the quality of care, by addressing knowledge gaps.

The need for evidence in primary care has been addressed in some studies to find gaps in research. Burgers et $\mathrm{a} \Gamma$ identified research questions for each ICPC-2 chapter through knowledge gaps in guidelines and input from stakeholders in the Netherlands. Muscat et $a^{\beta}$ analysed clinical questions submitted by GPs in Australia. A recent study analysed the grey literature concerning research studies in Portugal, to identify topics for a research agenda. ${ }^{9}$ Finley et

1. Unidade de Saúde Familiar Delta. Lisboa. Portugal.

2. Faculdade de Economia. Universidade de Coimbra. Coimbra. Portugal.

$\triangle$ Autor correspondente: Salomé Apitz. salapitz@gmail.com

Recebido: 07 de novembro de 2020 - Aceite: 12 de fevereiro de 2021 - First published: 20 de setembro de 2021 - Online issue published: 03 de janeiro de 2022 Copyright $\odot$ Ordem dos Médicos 2022 
al looked at the most prevalent conditions in primary care, allowing the identification of priority areas in need of guidelines and medical training. ${ }^{3}$ Furthermore, big data analysis of electronic health records in primary care databases has been proposed as a useful tool in healthcare management and research. ${ }^{10,11}$ The update of these databases is continuous, which makes them very suitable for discovering and monitoring healthcare trends. ${ }^{11}$

Despite the information available on common conditions in primary care, either through clinical studies or primary care databases, there might be a gap between frequent problems managed in primary care and published primary care research. A single study ${ }^{12}$ addressed this question in the Australian context, finding important discrepancies between literature and practice, but it is unclear if these findings are globally identical.

Scientometrics have been employed to perform empirical and quantitative analysis of a high volume of publications, to achieve an overview of the current status and trends in several research fields, which has proved useful in identifying research gaps. ${ }^{13}$ The analysis of research landscapes might therefore be used to complement the search for researchgaps in primary care.

The first aim of this study was to identify and analyse publication and citation trends concerning medical conditions, in primary care journals, published between 2010 and 2020. Secondly, we wanted to compare publication trends with the most common medical problems in primary health care, in Portugal and globally, to detect areas with publication and/or research gaps, to address the needs of primary care physicians.

\section{MATERIAL AND METHODS}

\section{Data source and search strategy}

We chose the Web of Science (WoS) search engine to retrieve recent literature related to primary care practice, due to its wide coverage, as it includes the MEDLINE database, and for offering powerful analysis tools, compared to other search engines. ${ }^{14,15}$

We accessed WoS on the 15th October 2020 and, since we were interested in global primary care research activity, the following search approach was employed: in an 'advanced search' topic (a field which includes title, abstract and author keyword we selected ('primary care' OR 'family practice' OR 'family medicine' OR 'general practice'), document type (article OR review), time span (2010 - 2020), source titles (primary care related journals), MeSH qualifiers related with clinical issues thus excluding qualifiers related with organizational and administrative issues (e.g. 'organization administration', 'history', 'economics', 'legislation jurisprudence'), database (MEDLINE), language (all). WoS citation files for the selected period were downloaded as 'full record and cited references' and saved in a 'tabdelimited' file format. The identified articles, with the corresponding titles, keywords, author information, abstracts, and references, were stored in a TXT format and the content was classified into major disease categories. The refer- ences not related with medical conditions were excluded.

To describe the Portuguese reality and explore the potential of electronic health records in research, after approval by the Portuguese Data Protection Authority, we assessed the Portuguese Primary Health Care Identity Card (BI-CSP), ${ }^{16}$ a health and clinical governance primary care database. We obtained and ranked data concerning active problems which was extracted from the problems list of users of primary health care centres of the Portuguese National Health Service. We categorized the data according to the International Classification of Primary Care $2^{\text {nd }}$ Edition (ICPC-2). ${ }^{17}$ We excluded the ICPC-2 code 'A98' for not being consistently considered a problem in the patient's problems list.

Furthermore, to obtain data on reasons for medical appointments and acute conditions that generally are not listed in problem lists, and to obtain a globally more relevant view, we searched WoS, PubMed, and Google Scholar for publications describing the most common problems in primary care, so we could make broader comparisons.

In terms of ethical issues, the study was not submitted to an Ethics Committee, since no intervention was made (which would require previous approval), patient data is anonymised, the Portuguese Data Protection Authority approved the access to the data, and secondary use of health data for research purposes is allowed by Portuguese law if the information is anonymized. As far as informed consent for data collection is concerned, it is given on an opt-out basis by citizens.

\section{Data analysis and presentation}

With the information obtained from WoS concerning the included articles, we used the open-source software VOSviewer ${ }^{18}$ to visualize the recent primary care research landscape. VOSviewer employs the visualisation of similarities (VOS) mapping technique, which can be used to create maps either based on a text corpus or based on networks such as citation networks. The VOSviewer network visualization option displays concepts based on their importance. The larger the label and the circle, the more important the concept is. The colour of the circle indicates the cluster to which the term belongs to. For each term that met the threshold, a relevance score was calculated, and based on this score, the most relevant terms were selected. In the present study, we analysed the co-occurrence of words using networking maps, based on the title and abstract fields.

Additionally, using the information extracted from WoS on the Publons publications tracking platform, ${ }^{19}$ we created a ranking of research areas with a greater number of published papers covering primary care conditions. Concurrently, with the information extracted from the BI-CSP, we created a ranking of active clinical problems in Portugal. We also listed the ranking of general categories for reasons for consulting a family physician co - Reasons for Visits (RFV) from Finley et al, ${ }^{3}$ a systematic review of 18 studies that included patient and physician reported reasons for visits as well as problems managed by physicians. 
Publications

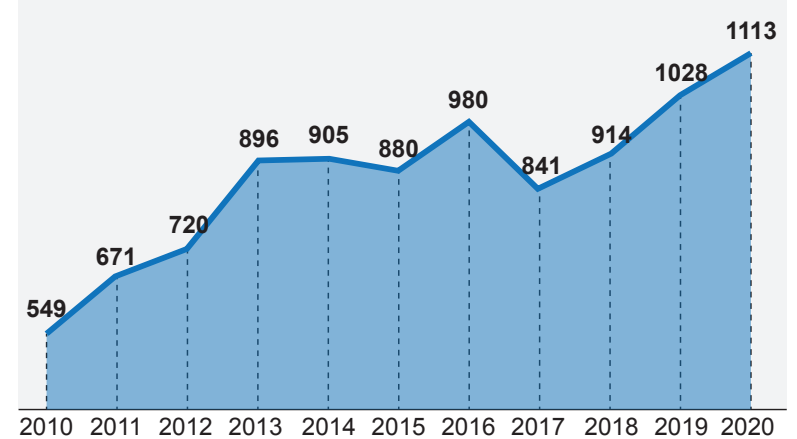

Citations

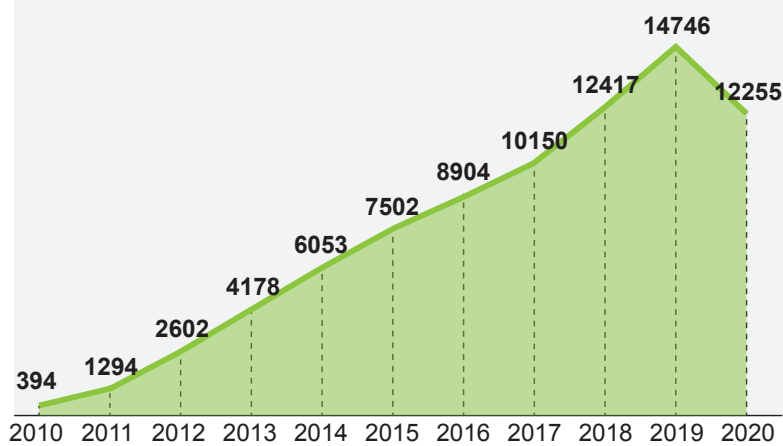

Figure 1 - Evolution of publications and citations in primary care journals

Then, the ranking of search findings was compared with both rankings, to assess whether the research effort in primary care is aligned with the occurrence of primary care issues.

\section{RESULTS}

\section{Publications and citations}

Our search of the primary care literature retrieved a total of 13388 original articles from the MEDLINE database, of which 9956 fulfilled the inclusion criteria. Fig. 1 shows the development of the yearly number of publications and citations among primary care journals. Despite some fluctuations, it is possible to appreciate a positive trend in the research carried out in this field over the past decade.

English was the key language of the primary care literature with 9332 documents (93.73\%), followed by Spanish $(6.22 \%)$ and French $(1.13 \%)$. The United Kingdom dominated the primary care literature with 4436 articles followed by the United States (2822), Australia (882), Canada (777), and Spain (633). According to Fig. 2, the most cited publications are from Europe (43.82\%), followed by North America (35.89\%), Asia (9.95\%), Australia (8.42\%), and South
America (1.91\%).

\section{Research areas, authors, institutions, and journals}

Excluding general scientific areas (e.g., health care sciences, Pharmacology, Health Economics), the most relevant clinical areas were Psychology (39.42\%), General Internal Medicine (26.03\%), Geriatrics (24.04\%), Paediatrics $(13.71 \%)$, and the cardiovascular system (9.71\%). Paul Little from the University of Southampton (UK) was the most productive author in this field: with 59 papers, he contributed to $0.59 \%$ of total scientific publications of primary care literature. The Nuffield Department of Primary Care Health Sciences from the University of Oxford (UK) was the leading institution, with 101 publications (1.01\%). The most productive authors and institutions were all found to be from developed countries. In Table 1 we identify the top 20 journals in terms of publications and Impact Factor. The British Journal of General Practice dominated the primary care literature and covered $13.30 \%$ of all documents, followed by BMC Family Practice (12.06\%), Family Practice (7.99\%), Canadian Family Physician (7.08\%), and Family Medicine (6.34\%).

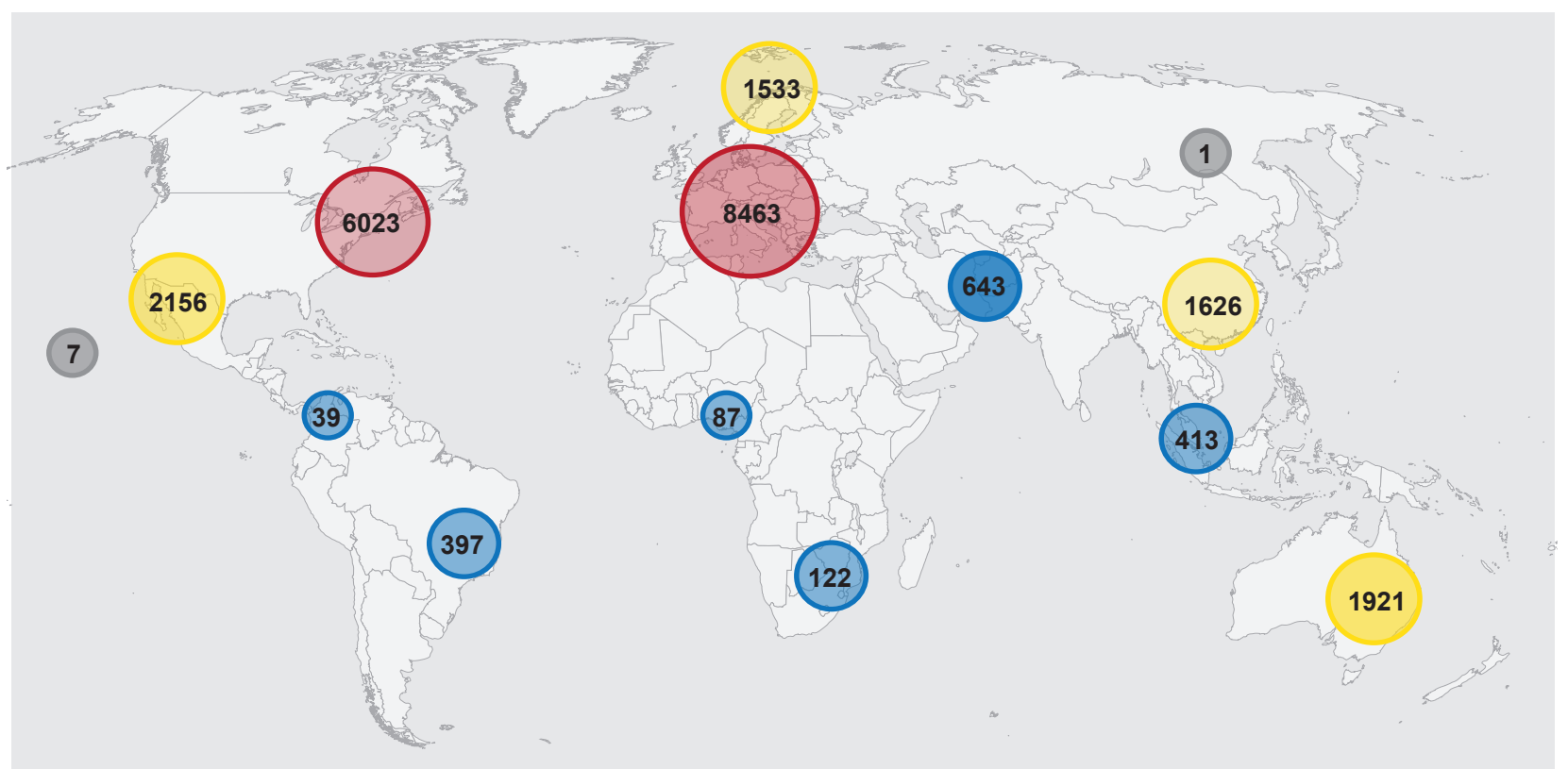

Figure 2 - Citation map regarding primary care publications 
Table 1 - Top 20 journals in terms of publications for primary care and their impact factors

\begin{tabular}{|c|c|c|c|}
\hline Source & Publications & $\%(n=9956)$ & Impact factor \\
\hline British Journal of General Practice & 1324 & 13.299 & 2.634 \\
\hline BMC Family Practice & 1201 & 12.063 & 2.550 \\
\hline Family Practice & 795 & 7.985 & 2.024 \\
\hline Canadian Family Physician & 705 & 7.081 & 1.538 \\
\hline Family Medicine & 631 & 6.338 & 1.162 \\
\hline Australian Family Physician & 576 & 5.785 & 0.690 \\
\hline Journal of the American Board of Family Medicine & 506 & 5.082 & 2.429 \\
\hline Annals of Family Medicine & 441 & 4.429 & 4.019 \\
\hline Atención Primaria & 396 & 3.978 & 1.177 \\
\hline Education for Primary Care & 395 & 3.967 & 0.726 \\
\hline Scandinavian Journal of Primary Health Care & 354 & 3.556 & 2.329 \\
\hline Journal of Family Medicine and Primary Care & 309 & 3.104 & 1.021 \\
\hline Primary Health Care Research \& Development & 290 & 2.913 & 1.072 \\
\hline Journal of Primary Care \& Community Health & 281 & 2.822 & 2.209 \\
\hline Semergen & 245 & 2.461 & 0.376 \\
\hline American Family Physician & 235 & 2.360 & 1.431 \\
\hline European Journal of General Practice & 231 & 2.320 & 2.439 \\
\hline Journal of Family Practice & 170 & 1.708 & 0.373 \\
\hline Australian Journal of General Practice & 162 & 1.627 & 0.871 \\
\hline Journal of Primary Health Care & 149 & 1.497 & 0.881 \\
\hline
\end{tabular}

\section{Scientometric network analysis}

The WoS search result containing summaries and tittles was uploaded to the VOSviewer software, applying the 'binary counting' technique. For the identification of the main issues of published research, a word co-occurrence analysis was performed. First, 756 treasure words were excluded (common keywords without scientific relevance). Then, using a filter considering 65 as the minimal number of term occurrences, we created a keyword network infographic according to keyword frequency. In this way, we could identify not only the most frequently used terms in literature, but also identify their relations, forming clusters of topics. Fig. 3 displays the areas in which we found more density concerning this field of study. It also identifies the main clusters, as well as the areas with more existing research. The five most frequently used keywords were 'depression', 'communication', 'pain', 'diabetes' and 'infection'.

Table 2 displays in detail the clusters that are more cited within every group. Cluster one represents common health problems of modern society, mainly cardiovascular conditions, related unhealthy lifestyles, and associated diseases. Cluster two embodies mental disorders, showing a clear connection with socioeconomic problems. Cluster three illustrates the duality between infection prevention and control. Cluster four explores oncology topics, with a focus on early diagnosis. Cluster 5 focuses on health management and related issues like doctor-patient relationship, leadership, patient safety, and satisfaction to guarantee an improvement in the quality of services provided by healthcare institutions to the community. According to Table 2 and Fig.
3, we identified some decentralized topics, corresponding to areas without a significant amount of studies, such as 'palliative care, chronic pain, chronic illness, sleep (and insomnia), lifestyle change, children, prostate cancer, heart disease, antibiotic prescribing, burnout, quality improvement, breast cancer, vaccine, mental disorders, blood pressure control, osteoporosis, chronic disease management, osteoarthritis, doctor-patient relationship, primary care management and COVID', which represent potential areas for future research.

\section{Comparing research with practice}

Comparing the main scientific areas of the papers extracted from MEDLINE, with the coding of active problems in Portugal (June 2020), it is possible to notice that there are some discrepancies between the publication efforts of Primary Care journals and the most frequent active problems that health professionals face in the Portuguese context. A discrepancy can also be noted when in the internationally acknowledged RFV. In Table 3, we can visualize some gaps between the publication landscape and clinical conditions.

Considering the MEDLINE classification, the research areas with most publications are General Internal Medicine $(27.10 \%)$, Cardiology $(10.10 \%)$, Sociology $(8.90 \%)$, Psychiatry (8.20\%), and Neurosciences/neurology (7.80\%). On the other hand, areas such as Ophthalmology $(0.70 \%)$, Otorhinolaryngology $(1.70 \%)$, Haematology $(2.40 \%)$, Dermatology $(2.70 \%)$, and Reproductive Biology $(2.50 \%)$ are the areas with the least amount of publications.

By analysing the active problems in the Portuguese 


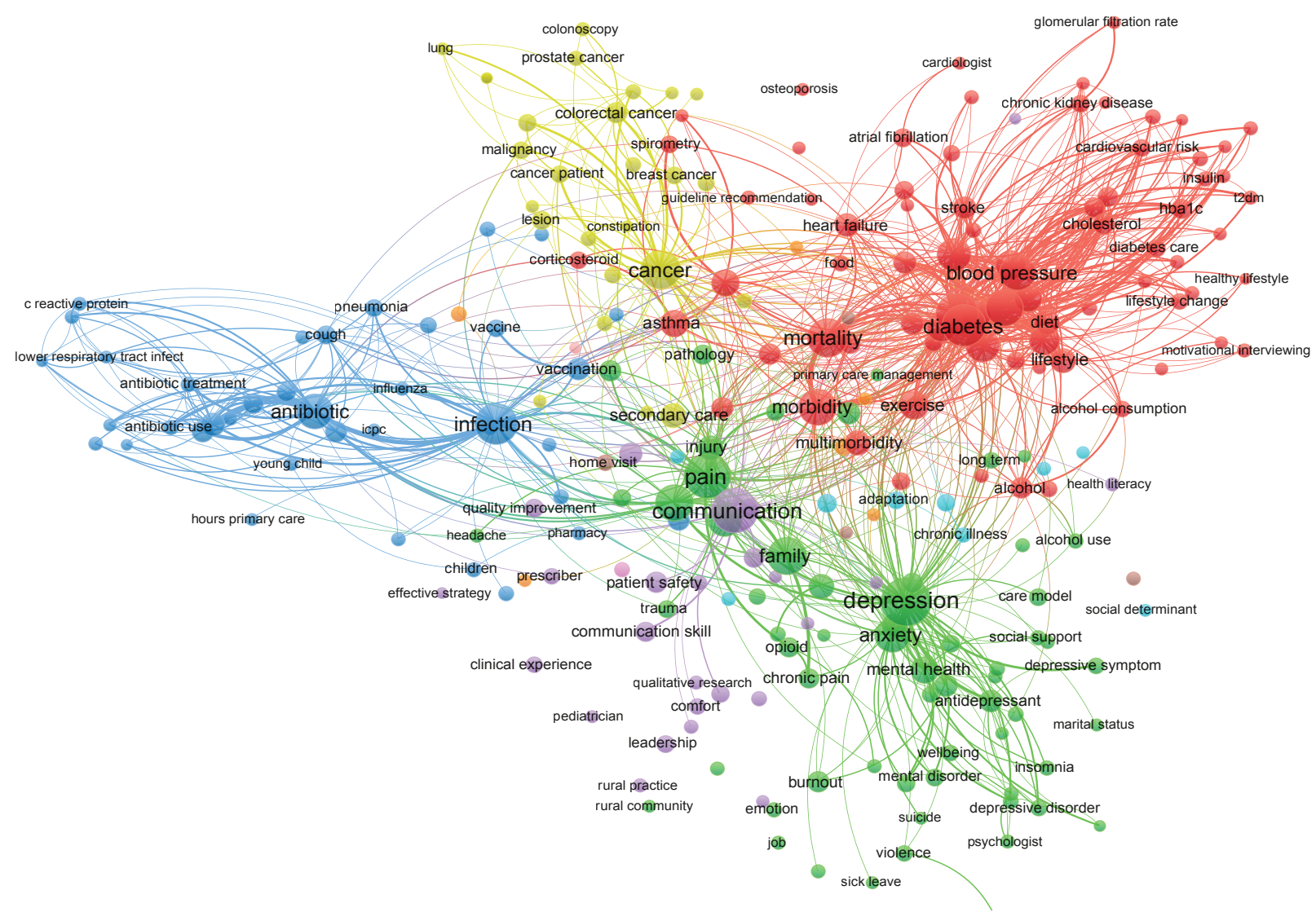

Figure 3 - Map of relations concerning primary care publications

context, we find a different ranking order. The most prevalent health issues (classified according to MEDLINE search areas) are related with orthopaedics (15.60\%), endocrinology metabolism $(12.90 \%)$, Cardiology $(9.70 \%)$, respiratory system $(9.40 \%)$, and Gastroenterology/hepatology $(9.30 \%)$. On the other hand, clinical issues related with scientific areas such as Sociology (1.00\%), Haematology $(1.10 \%)$, male reproductive biology $(1.50 \%)$, Otorhinolaryngology $(2.10 \%)$, and Neurosciences/neurology $(2.40 \%)$ have a lower frequency.

Therefore, by comparing the research efforts and the active problems in Portugal, which mainly correspond to chronic conditions, it is possible to identify the research areas where scientific publication in Primary Care journals is taking place with a higher proportion considering the needs that arise from clinical practice, namely in areas like Sociology $(\Delta=+8.00 \%)$ and Neurosciences/neurology. In contrast, a lower publication rate concerning areas with clinically higher demands is seen in areas such as Orthopaedics $(\Delta=-12.40 \%)$, Endocrinology metabolism ( $\Delta=-6.40 \%)$, Gastroenterology hepatology $(\Delta=-5.50 \%)$, Dermatology $(\Delta=-3.50 \%)$, and Ophthalmology $(\Delta=-2.10 \%)$.

Finally, Table 3 also presents an RFV ranking obtained from the work developed by Finley et al. ${ }^{3}$ Although the overlap between the classification from Finley et al and the MEDLINE search areas was not always possible, we also identify, qualitatively, some areas with lower publication out- put compared to their burden in terms of reasons for visit, with the respiratory, dermatology, and orthopaedic areas being the most relevant.

Furthermore, we observe an expected difference between the rankings of the active problems and the RFV, showing a higher prevalence of the areas of the respiratory system and nervous and sense organs in the RFV column, probably related to acute infections and Ear-Nose and Throat problems. In contrast, musculoskeletal problems are proportionally less common.

\section{DISCUSSION}

The present study identifies the leading countries, journals, and subjects, aside from relationships between prevalent topics among publications in Primary Care journals. There is growing scientific production in the field of primary care, showing a global interest in this field. The United Kingdom and the USA are the main contributors to scientific output, with Europe and North America being the regions with the highest number of citations. The fact that developed countries dominated the research landscape gives strength to our comparison with the Portuguese reality.

The keyword analysis identified 'depression', 'communication', 'pain', 'diabetes' and 'infection' to be the most frequent terms and found five clusters - $1^{\text {st }}$ cardiovascular conditions and other conditions related with unhealthy lifestyles; $2^{\text {nd }}$ mental disorders; $3^{\text {rd }}$ infections; $4^{\text {th }}$ oncology and 
Table 2 - Most relevant clusters on primary care research

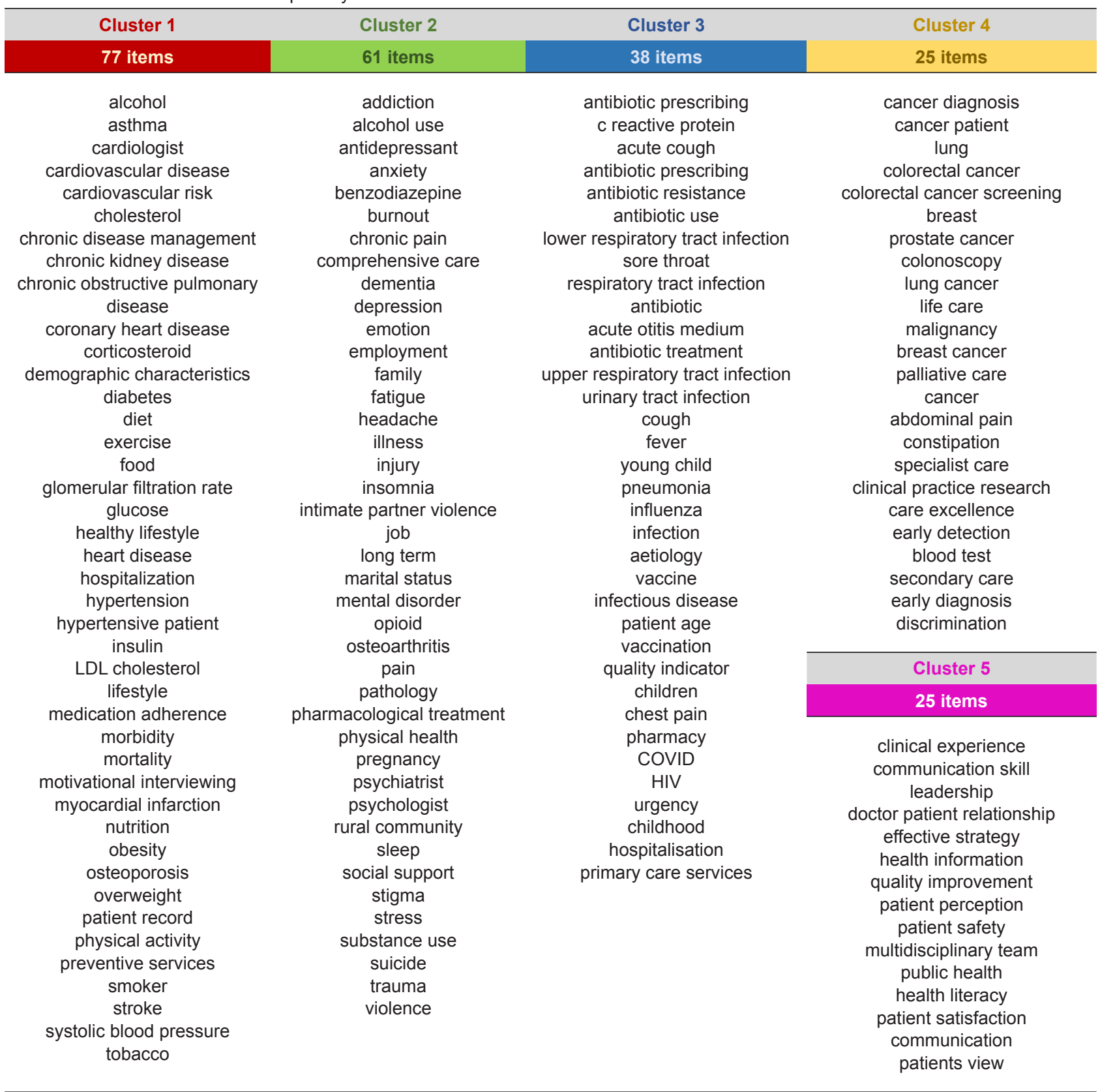

$5^{\text {th }}$ health management.

Furthermore, we identified and ranked the most common active problems in Portuguese primary care practice and compared their relative frequency with the relative frequency and ranking of the search topics. In order to cover the information about potential acute problems, we ranked the reasons for visit. Since no relative frequencies regarding this topic were available, no gap analysis was performed. Some difficulties arose concerning the correspondences between groups. The categories 'Cancer', 'Infectious/parasitic', 'Injury/poisoning', 'supplementary classification' had no direct match. We also considered the correspondence between the search topic 'General Medicine' and 'General and non-specific' imperfect and not representative of reality.

Nonetheless, whilst the use of different classification systems among the three data sources presented challenges in combining and comparing data, the findings seem consistent, in with some areas being under-represented in Primary Care journals and are probably not meeting the needs of primary care physicians. Concerning both, the active problems and the internationally acknowledged reasons for visit, the clinical areas of the Musculoskeletal System; Endocrine, Metabolic and Nutrition; Digestive and Respiratory Systems, and Skin were identified as having the largest discrepancies. Some of these areas might be covered by other journals and international guidelines, which is the case, for example, with diabetes, asthma, and chronic obstructive pulmonary disease.

Similar research gaps were described by other authors. Cooke et $a^{12}$ found that the research output of the journal 

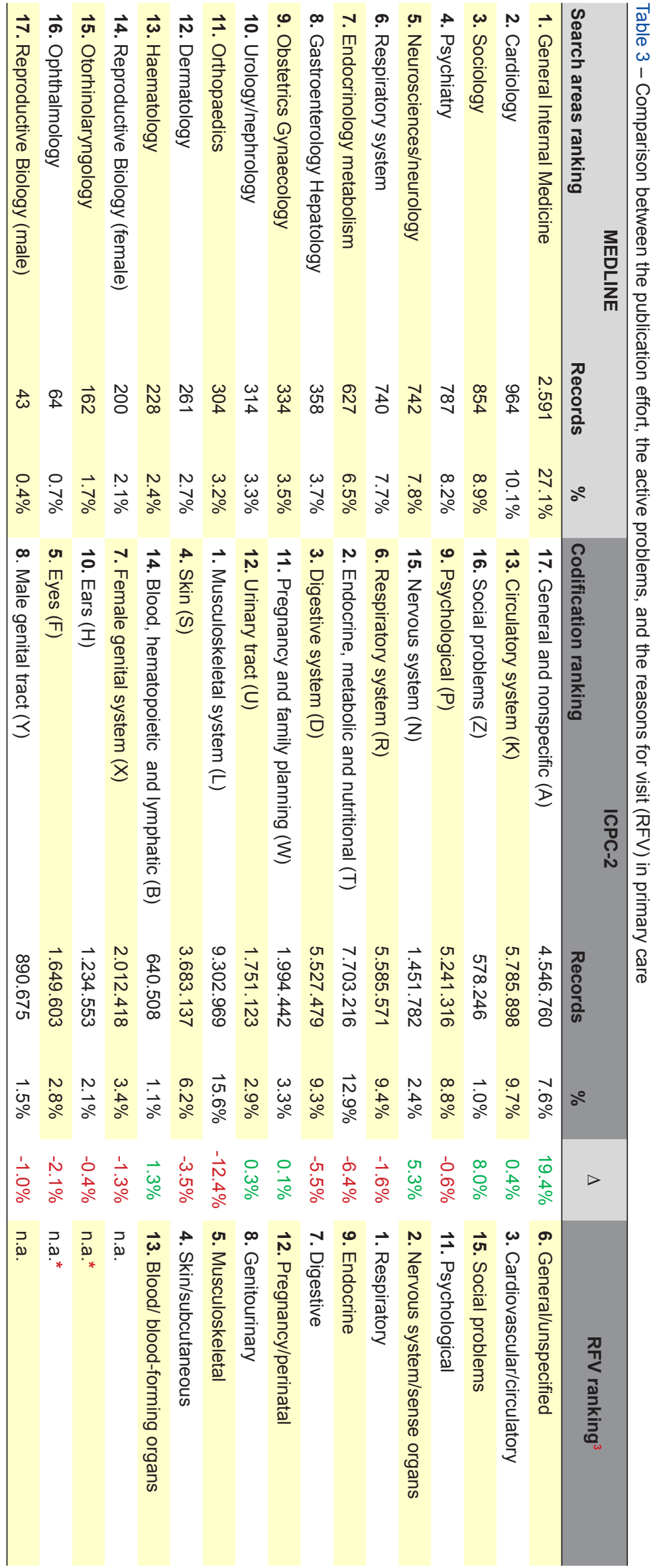

Australian Family Physician and Guidelines were not aligned with the problems GPs most commonly face, with the topics hypertension, immunization, upper respiratory tract infection, depression, osteoarthritis and back pain showing relevant gaps. Burgers et $a /$ created a research agenda through surveys among GPs and found similar research needs, with the highest number of research questions being related with the areas of musculoskeletal, psychological, skin, and general and unspecified ICPC-2 areas, and most of the research topics concerning common conditions. Muscat et $a^{\beta}{ }^{\beta}$ coded clinical questions from GPs according to ICPC2, finding that the most frequently endorsed questions belonged to the endocrine/metabolic and nutritional chapter headings, followed by the general and unspecified, the digestive and the musculoskeletal chapters.

After analysing the map of relations (Fig. 3) and taking into consideration the ranking of active problems and reasons for a medical appointment, our study identified some potential topics for future research such as palliative care, chronic pain, motivational interviewing, lifestyle change, chronic disease management, quality improvement, sleep (and insomnia), antibiotic prescribing, burnout, breast cancer, vaccine, mental disorders, blood pressure control, osteoporosis, osteoarthritis, doctor-patient relationship, primary care management, COVID, among others.

To our knowledge, this is the first systematic mapping of the output of research topics in Primary Care journals.

The present study acknowledged potential research and publication gaps in Primary Care journals, identifying areas eligible for a higher number of publications as well as potential research topics. Although we acknowledge that primary care research might be published in journals from other fields and that physicians might access other sources of information, given the increasing amount of evidence, aggregating relevant information from the main primary care journals seems relevant to help clinicians stay up to date.

Considering that our findings overlap with findings from authors that explored research gaps, the use of scientometric analysis and comparison with common problems could be a strategy to recognize areas with research gaps in Primary care. The findings might also help to direct continuing medical education and help with guideline development. 


\section{Limitations and further research}

This article presents the usual limitations of a scientometric study. The analysis was narrowed to studies and structured data collected from Web of Science regarding Journals indexed at MEDLINE. Therefore, only the articles published in those journals were analysed. Nevertheless, we consider that MEDLINE is the most accredited medical data base and provides an overview of the most relevant literature. ${ }^{20}$

Additionally, the search applied mainly big data tools, so an individualized assessment of each publication title and abstract was not done and only the title and abstract were considered, possibly missing some information, with the scientific quality of the studies not being considered. We also only analysed general fields and subtopics but could not identify specific research questions. The Dutch approach described by Burgers et al. and applied to single areas could be useful in defining concrete questions.

The data extracted from BI-CSP only contains information concerning the active problem lists, thus ignoring routine health care visits and preventive services as well as acute problems, that are not usually coded as problems on those lists. Furthermore, it only looks at the Portuguese reality; comparisons with primary care databases from other countries could prove useful. There could be a coding bias, favouring the coding of problems with associated health programs (diabetes and hypertension), as well as problems associated with pay for performance incentives (tobacco use; excessive weight, obesity). These problems could thus be overrepresented when compared to other codes that are frequently ignored, such as cataract or refractive error, despite its high prevalence in primary care. This approach also does not take into account a potential undercoding and underdiagnosis, although both may indicate a possible lack of knowledge and, by itself, a greater need for disclosure in the respective fields, thus not compromising the findings. We also recognise that primary care research can be published in journals from other fields and thus might have been excluded in this study.

\section{REFERENCES}

1. Hannaford P, Smith B, Elliott E. Primary care epidemiology: its scope and purpose. Fam Pract. 2006;23:1-7.

2. Alper BS, Hand JA, Elliott SG, Kinkade S, Hauan MJ, Onion DK, et al. How much effort is needed to keep up with the literature relevant for primary care? J Med Libr Assoc. 2004;92:429-37.

3. Finley CR, Chan DS, Garrison S, Korownyk C, Kolber M, Campbell S, et al. What are the most common conditions in primary care? Systematic review. Can Fam Physician. 2018;64:832-40.

4. Hajjar F, Saint-Lary O, Cadwallader J, Chauvin P, Boutet A, Steinecker $M$, et al. Development of primary care research in North America, Europe, and Australia from 1974 to 2017. Ann Fam Med. 2019;17:49-51.

5. Manski-Nankervis J, Sturgiss E, Liaw S, Spurling G, Mazza D. General practice research: an investment to improve the health of all Australians. Med J Aust. 2020;212:398-400.e1.

6. López-Torres Hidalgo J, Basora Gallisá J, Orozco Beltrán D, Bellón Saameño JÁ. Mapa bibliométrico de la investigación realizada en atención primaria en España durante el periodo 2008-2012. Aten Primaria. 2014;46:541-8.

7. Burgers JS, Wittenberg J, Keuken DG, Dekker F, Hohmann FP, Leereveld D, et al. Development of a research agenda for general practice based on knowledge gaps identified in Dutch guidelines and

\section{CONCLUSION}

While the number of publications in primary care journals has been increasing, the distribution of publications in Primary Care journals does not correspond to the problems faced in clinical practice, especially in the fields of musculoskeletal disease, dermatology, digestive and respiratory systems, and ophthalmology. The use of scientometric analysis to identify publication trends and its comparison with common problems could be a strategy to recognize areas with research gaps in Primary Care.

\section{AUTHORS CONTRIBUTION}

SA: Draft of the protocol, literature review, data processing, draft and review of the paper, approval of the final version.

PF: Conception of the methods, statistics section, data processing, draft and review of the paper, approval of the final version.

\section{PROTECTION OF HUMANS AND ANIMALS}

The authors declare that the procedures were followed according to the regulations established by the Clinical Research and Ethics Committee and to the Helsinki Declaration of the World Medical Association, updated in 2013.

\section{DATA CONFIDENTIALITY}

The authors declare having followed the protocols in use at their working center regarding patients' data publication.

\section{COMPETING INTERESTS}

The authors declare that they have no conflict of interest regarding this article.

\section{FINANCING SOURCES}

There were no external sources of financing for the present research.

input from 48 stakeholders. Eur J Gen Pract. 2019;25:19-24.

8. Muscat D, Patel P, Reid S, Hoffmann T, Albarqouni L, Trevena L. Content analysis of clinical questions from Australian general practice which are prioritised for answering: identifying common question types and perceived knowledge gaps. BMJ Evid Based Med. 2020;25:15-21.

9. Abreu J, Reis P, Cardoso S, Reis S. Research on the field of family medicine in Portugal: preferred areas of investigation and gaps. Rev Port Med Geral Fam. 2020;36:408-14.

10. Vezyridis P, Timmons S. Evolution of primary care databases in UK: a scientometric analysis of research output. BMJ Open. 2016;6:e012785.

11. Canaway R, Boyle DI, Manski-Nankervis JE, Bell J, Hocking JS, Clarke $\mathrm{K}$, et al. Gathering data for decisions: best practice use of primary care electronic records for research. Med J Aust. 2019;210:S12-6.

12. Cooke G, Valenti L, Glasziou P, Britt H. Common general practice presentations and publication frequency. Aust Fam Physician. 2013;42:65-8.

13. Wang M, Liu P, Zhang R, Li Z, Li X. A scientometric analysis of global health research. Int J Environ Res Public Health. 2020;17:2963.

14. MEDLINE on Web of Science. [accessed 2020 Oct 15]. Available from: https://clarivate.com/webofsciencegroup/solutions/webofsciencemedline/. 
15. Van Eck N, Waltman L. Software survey: VOSviewer, a computer program for bibliometric mapping. Scientometrics. 2010;84:523-38.

16. Serviço Nacional de Saúde. Bilhete de Identidade dos Cuidados de Saúde Primários. [accessed 2020 Oct 15]. Available from: https://bicsp. min-saude.pt/.

17. Classification Committee of the World Organization of Family Doctors.
ICPC-2: International Classification of Primary Care. $2^{\text {nd }}$ ed. Oxford: Oxford University Press; 1998.

18. VOSviwer. VOSviewer - visualizing scientific landscapes. [accessed 2020 Odt 15]. Available from: https://www.vosviewer.com/.

19. Publons. The home of expert peer review. [accessed 2020 Oct 15] Available from: https://publons.com. 